\title{
Review: prophylactic use of vitamin $D$ reduces falls in older persons
}

Bischoff-Ferrari HA, Dawson-Hughes B, Willett WC, et al. Effect of vitamin D on falls: a meta-analysis. JAMA 2004;291:1999-2006.

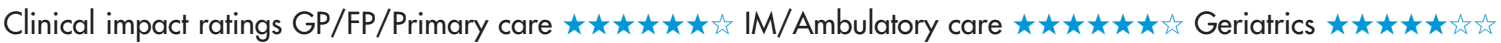

In older persons, is prophylactic use of vitamin D effective for preventing falls?

\section{METHODS}

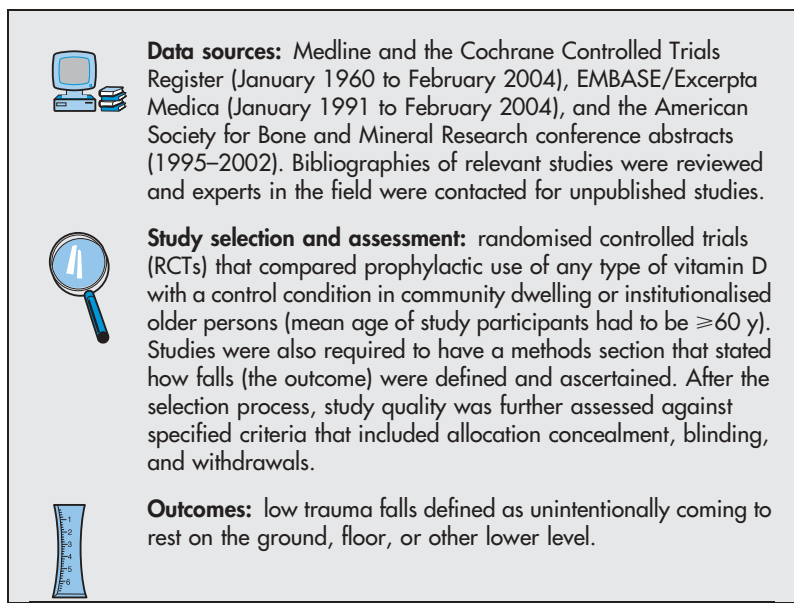

\section{MAIN RESULTS}

5 RCTs $(\mathrm{n}=1237)$ (mean age 70y, 81\% women) met the selection criteria. Comparisons included cholecalciferol, 800 IU/day plus calcium, $1200 \mathrm{mg} / \mathrm{day}$ with calcium, $1200 \mathrm{mg} /$ day (2 RCTs); cholecalciferol, $400 \mathrm{IU} /$ day plus calcium, 800 to $1000 \mathrm{mg} /$ day from diary products with placebo ( $\mathrm{l}$ RCT); calcitriol, $0.5 \mu \mathrm{g} /$ day with placebo ( 1 RCT); and $1 \alpha$-calcidiol, $1 \mu \mathrm{g} /$ day with placebo ( 1 RCT). Meta-analyses were done using fixed and random effects models. Both analyses showed that fewer patients in the vitamin D group than in the control group had $\geqslant 1$ fall (table). Furthermore, a sensitivity meta-analysis of the 10 "potentially appropriate for inclusion RCTs" (10 001 participants) showed that fewer patients in the vitamin D group than in the control group had $\geqslant 1$ fall (relative risk reduction $13 \%, 95 \%$ CI 4 to 20 ).

For correspondence: $\mathrm{Dr} \mathrm{H}$ A Bischoff-Ferrari, Brigham and Women's Hospital, Boston, MA, USA. hbischof@hsph.harvard.edu

Sources of funding: Harvard/Harford Foundation; Charles A. King Trust Fellowship Award; Irene and Fredrick Stare Nutrition Education Fund; Swiss Foundation for Nutrition Research; International Foundation for the Promotion of Nutrition Research and Nutrition Education.

\section{CONCLUSION}

In older persons, prophylactic use of vitamin $\mathrm{D}$ is effective for reducing falls.

Abstract and commentary also appear in ACP Journal Club.

\section{Commentary}

- alls are a serious concern in older persons because of their high prevalence and potential to lead to severe morbidity or mortality. Any intervention to decrease this epidemic would be welcome. The meta-analysis of $5 \mathrm{RCTs}$ by Bischoff-Ferrari et al suggests that a daily supplement of vitamin D can reduce falls in older persons by $19 \%$. A number needed to treat of 15 is impressive and the inexpensive cost of vitamin D supplementation makes this recommendation even more compelling.

Are there any cautions to a program of vitamin D supplementation in older adults? Perhaps if one is reluctant to treat while a mechanism of action is yet to be determined. The authors cite a plausible argument that vitamin $D$ enhances muscular strength, noting evidence for muscle cell growth after stimulation of the "highly specific nuclear vitamin D receptor" in human muscle. Indeed, the rapid onset of benefit (in 2-3 mo in 2 of the selected 5 RCTs) parallels results seen in studies emphasising exercise intervention,' which has a somewhat more easily understood mechanism of action on muscle.

3 of the 5 RCTs stipulated calcium supplementation along with vitamin D. Hypercalcaemia was not reported, and of the 4 trials that measured postintervention concentrations of vitamin $D$, no cases of hypervitaminosis D occurred. However, use of calcium supplementation and the optimal dose of either calcium or vitamin D are unclear.

A recent Cochrane review of falls in the elderly ${ }^{2}$ lists risk factor intervention, muscle strengthening and balance training, and withdrawal of psychotrophic medications as interventions "likely to be beneficial." Such steps should certainly be continued. Now, healthcare providers should consider routine vitamin $D$ supplementation for older persons as recommended by Bischoff-Ferrari et al in this review.

Bruce E Johnson, MD Brody School of Medicine at East Carolina University Greenville, North Carolina, USA

1 Campbell AJ, Robertson MC, Gardner MM, et al.' Randomised controlled trial of a general practice programme of home based exercise to prevent falls in elderly women. BMJ 1997;315:1065-9.

2 Gillespie LD, Gillespie WJ, Robertson MC, et al. Interventions for preventing falls in elderly people. Cochrane Database Syst Rev 2003;(4):CD000340.

Vitamin D prophylaxis $v$ a control condition (eg, calcium or placebo) in older persons at 3 months to 3 years*

\begin{tabular}{|c|c|c|c|c|c|}
\hline \multirow[b]{2}{*}{ Outcome } & \multirow[b]{2}{*}{ Number of trials $(\mathrm{n})$} & \multicolumn{2}{|c|}{ Weighted event rates } & \multirow[b]{2}{*}{$\operatorname{RRR}(95 \% \mathrm{Cl})$} & \multirow[b]{2}{*}{ NNT (CI) } \\
\hline & & Vitamin D & Control & & \\
\hline Participants who had $\geqslant 1$ fall & 5 (1237) & $30 \%$ & $37 \%$ & $19 \%(6$ to 31$)$ & 15 (9 to 52$)$ \\
\hline
\end{tabular}

